\title{
Beyond borders: Steering metropolitan growth priorities through spatial imaginaries
}

Borders and boundaries are practical ways of organising spatial relations in metropolitan regions. They usefully define administrative divisions between local government areas, informing the constraints of land-use plans, and describe individual sites necessary for the transaction and development of property and land. However, functional divisions of space are not always clear cut. Contemporary challenges of urbanisation and globalisation often ignore administrative-political boundaries, thus statutory divisions of space are required to be woven into other functional spatial layers drawing attention to the strategic-statutory interface of planning systems and governance arrangements.

Although not new, experiments with spatial imaginaries have accelerated, and have become central to metropolitan strategies. In Sydney, the Greater Parramatta and Olympic Peninsula functional economic corridor introduces both new mechanisms for implementation and statutory weight on top of strategic direction. We draw attention to the way this spatial imaginary utilises (or ignores) existing borders and boundaries in an attempt to rebalance the spatial structure of the metropolitan region. Through this case study, we highlight the challenges of rebalancing the Sydney metropolitan region, and the broader implications that emerge through the use of spatial imaginaries.

Key words: borders; spatial imaginaries; metropolitan governance; Sydney metropolitan region

\section{Introduction}

The governance of metropolitan regions are prominent urban issues dominating discussions around the strategic development of cities and regions (Tomlinson and Spiller 2018; Hamnett and Freestone 2017). Debates and conflicts often ensue regarding what is the 'right' scale of government and governance to manage growth in metropolitan regions. In Australia, jurisdictional conflicts are seen in the rebordering of local government area (LGA) boundaries (Dollery, Grant and Kortt 2013). These conflicts are politicised and attract varying levels of attention, often justified through increased efficiency and savings associated with service delivery and administration. However, the evidence is not clear cut and can vary depending on analytical criteria (Grant, Ryan and Lawrie 2015; ILGRP 2013). While we are aware of these conflicts taking place at the coterminous edge of LGA boundaries, more complex processes are underway, underscoring the governance of spatial imaginaries. In response to enduring multilevel and metagovernance challenges of coordinating land-use planning, infrastructure provision and integrated development, spatial imaginaries are invented to draw together and mediate relations between contentious political actors (Hincks, Deas and Haughton 2017). 
Spatial imaginaries - the invention and use of these spaces in planning documents - have increased markedly since the 1950s, from local through supranational scales internationally (c.f. Haughton and Allmendinger 2017; Metzger and Schmitt 2012). These processes are also underway in Australia (Pham 2018; Steele, Alizadeh and Eslami-Andargoli 2013). This article examines experiments with spatial imaginaries exploring their role in managing metropolitan growth priorities through a particular spatial imaginary, the Greater Parramatta and Olympic Peninsula (GPOP) functional economic corridor (FEC) in the Sydney metropolis.

The GPOP, as a strategically important growth centre is an opportune space to test these mechanisms. It is also an increasingly complex space in the middle of several spatial imaginaries. Although these experiments have accelerated, the use of spatial imaginaries can be traced to the earliest metropolitan plan, the County of Cumberland Planning Scheme (CCPS) (1948). These spatial innovations have evolved in response to contemporary urban challenges, expanded and ordered against a hierarchy of activity centres, priority precincts and at the top of the metropolitan pile, FECs.

FECs are particularly interesting soft spaces of strategic importance. As they are becoming increasingly prominent in the governance, planning and development of metropolitan regions, critical attention to their development is warranted (Allmendinger and Haughton 2009). Indeed, they are a notable feature of many contemporary spatial development strategies (Metzger and Schmitt 2012). While FECs are central to achieving metropolitan strategies, they also transect across multiple scales (Haughton and Allmendinger 2017). This scalar extensiveness is reflective of the ambition of metropolitan strategic planning, thus requiring greater exploration into the scalar relationships between local, metropolitan and global developmental drivers and their subsequent impact on metropolitanisation in Sydney (Pham 2018). While these spaces are strategically significant and central in responding to the challenges of managing metropolitan growth priorities, the fuzzy boundaries of strategic plans hide the messiness at the edges of statutory boundaries when they overlap. Once this veil is lifted, conflicts materialize as new statutory boundaries do not tessellate with existing statutory borders (Pugalis and Townsend, 2014). Thus, when the soft-spaces and boundaries of metropolitan strategies harden, the rhetoric of strategy moves closer to reality, requiring closer engagement with planning conflicts.

The methodology used in this article is informed by an interpretive policy analysis approach (Yanow 2007). Spatial imaginaries, as strategic devices cannot be directly observed - this quality is a challenge to social and spatial research, but this is also where interpretive research methodologies are appropriate tools to understand and analyse objects shaping social realities (Yanow 2006). This article builds on previous research identifying spatial imaginaries as more than just superficial representations, but as strategic devices shaping government decision-making (Hincks, Deas and Haughton 2017). A range of strategic plans were identified and analysed that acknowledged the importance of FECs as important actors within metropolitan strategies. Analysis of spatial representations - that is - spatial imaginaries were also central to this investigation and were analysed historically from strategic plans since the 
1960s and also considered their intersection with, for example, local government area boundaries, which identified spatial conflicts that emerged in the research.

This article is structured in four sections. Section One provides the theoretical scaffold to support this investigation by providing a critical review of literature engaging with spatial imaginaries and the importance of borders shaping their strategic and territorial extent. Section Two identifies the emergence of FECs and spatial imaginaries in Sydney's earliest metropolitan strategic plans and traces the hardening of a strategically significant FEC through to the 2018 metropolitan strategy. Section Three draws attention to the importance of where the border of these strategically significant spatial imaginaries are drawn, what criteria informs their delineation, and why they might develop a statutory outline in addition to their strategic relevance in addressing metropolitan growth priorities. We focus in particular the complexities of apportioning contributions to infrastructure development within the GPOP. The final section highlights the importance of spatial imaginaries: how they interact with existing planning spaces; and why these spaces require critical engagement in response to future planning challenges.

\section{Spatial imaginaries and their borders}

Planning and planners simultaneously work across multiple scales and spaces. They respond to social and spatial challenges, shaping regional identities, steering regional development, or resolving land-use dilemmas (Hamnett and Freestone 2018). These responsibilities require social and spatial sensitivity to consider and balance conflicts between stakeholders and outcomes from steering development through strategy. We can categorise the role of planning by working with 'soft', strategic spaces open to greater levels of interpretation and fuzziness and more clearly political, and 'hard' statutory spaces which provide a clear demarcation of space which is more clearly juridical (Hubbard and Prior 2018).

Spatial imaginaries provide idealised visions of existing realities, often drawing a distinction between the 'soft' spatial imaginaries, and 'hard' territorial spaces (Haughton and Allmendinger 2015). Soft spatial imaginaries are readily utilised, and increasingly so, paired with policies and strategic content to steer metropolitan growth priorities. While spatial imaginaries have been analysed in the Australian context (see Baker and Ruming 2015; Steele and Ruming 2012), they have lacked sufficient attention. We can look to European examples for a more extensive exploration and interrogation in a global context (c.f. Allmendinger and Haughton 2017; Haughton and Allmendinger 2008; Haughton et al 2010; Healey 2007; Metzger and Schmitt 2012). Besides the practical potential, there is a political attractiveness of spatial imaginaries due to their imprecision (Hincks, Deas and Haughton 2017). This is not to say that spatial imaginaries are inaccurate in determining or complementing the spatial extent of a given policy, but as they can be interpreted from a range of different perspectives there is significant flexibility of interpretation. However, this imprecision requires cooperation and collaboration with a range of spatial actors including various levels of government, government departments, institutional actors and communities to support and carry out area-based strategies (Haughton and Allmendinger 2017). 
While considering the extent and performance of spatial imaginaries, we may consider them both bounded and boundless, thus necessitating engagement with a theory of the border. The delineation and alignment of borders, like spatial imaginaries are polymorphic, subject to change (Burridge et al. 2017). Often constructing distinctions between 'Us' and 'the Other' (Paasi 2009, p. 218), bordering leads to rebordering processes which are territorially based, but often shaped by politics, strategy, rhetoric and identity (Anderson and O'Dowd 1999). Historically speaking, stable borders are an exception rather than a rule. Borders are shaped by macroscopic drivers such as globalisation, and more locally in response to area-based development priorities. Thus, a dialectic tension between universal and particular must be considered when adopting a theory of borders (Paasi 2009).

This brief interlude casts a light on the inherent challenges involved when utilising spatial imaginaries in the discipline of planning. It is this contentious space of the FEC where greater deliberation of the incoherencies of spatial planning within metropolitan regions can take place. In particular relevance to this article, a dialogue is developed around the intersection of strategic and statutory borders where both territorial and relational understandings of space (Allmendinger et al. 2015) can be considered. Although perspectival conflict is inevitable when engaging with spatial imaginaries with fuzzy borders (Paasi and Zimmerbauer 2015), of greater relevance to this case study are spaces which not only attract perspectival difference, but also involve a collection of overlapping statutory spaces.

Metropolitan regions in Australia serve multiple functions, balancing place-based development and concentrating sectoral specialisations to be embedded in networks of global capital. This leads to a multiplication of layers of governance where spatial fixes are required to resolve strategic and developmental challenges (Blatter 2004). FECs acting as spatial fixes, mediate political, social, ethnic and economic differences (Newman 2011), materialising a space to resolve the 'messiness' around borderlines and boundaries (Steele, Alizadeh and Eslami-Andargoli 2013, p. 96). As regions grow, the influence of global drivers become concentrated in place. These effects also shape institutional relations at the local, city and regional level (Swyngedouw 2004) and the prioritisation of global competitiveness shapes how local spaces are developed. This restructuring process is inherently political, contested and reveal tensions as the fate of these spaces are determined. For example, while statutory boundaries offer clearly defined land-use constraints to draw coherence within a specified area, project specific determinations and deal-based outcomes can also occur such as spot rezoning allowing proponents to develop beyond the statutory provisions which are drawn (Gurran and Ruming 2016). Thus, while exceptions can occur within a single statutory space, introducing overlapping statutory spaces compound these conflicts requiring the involvement of bespoke governance actors or more complex mediation processes. In Sydney, the Greater Sydney Commission (GSC) performs this responsibility as a metropolitan governance actor, steering strategies and development, and responding to planning conflicts. The next section traces the changing composition and role of spatial imaginaries in Sydney's metropolitan strategies identifying how they may be utilised to manage growth in the metropolis. 


\section{Spatial imaginaries in Sydney's metropolitan strategic plans}

While the role of spatial imaginaries has been mapped in Sydney's contemporary metropolitan strategic plans previously (Pham and Pugalis 2019), this paper instead draws relations between the use of spatial imaginaries, through the corridor concept in Sydney's earliest metropolitan plan, the CCPS 1948, and its evolution towards a statutory FEC in the 2018 Sydney metropolitan strategic plan.

While the CCPS imported the spatial imaginary of the 'green belt' from the UK, the most relevant historical precedent to contemporary FECs is the corridor introduced in the Sydney Region Outline Plan (SROP) (1968). These special use corridors were both intensive and extensive - reserved to extend public utilities and developing principles for guiding megaregional corridors connecting regional centres of Wollongong and Newcastle (NSW SPA 1968, p. 16). What is important within these strategies is the contingency of where hard utilities (e.g. water reticulation) and transport infrastructure are located. These corridors 'avoided precise boundaries but used existing transport routes as spines and existing towns as nodes of growth' (Morison 2000, p. 126). It is the location of these investments that determined where settlements were planned, compromising growth management priorities with locational preferences (c.f. Spearrit and DeMarco 1988).

While corridors can encompass a range of scales (local to supranational), function (ecological, transportation, economic) and perspective (geography, spatial policy, economic) they generally refer to the 'development of macro-scale development structures' (Albrechts and Tasan-Kok 2009, p. 298). In these early metropolitan plans, concepts of the corridor (green belt) were applied as imported policies, without translation. While the marketing of the green belt was idealistic, greater contextualisation of its impact was required to identify the barriers to its implementation. 


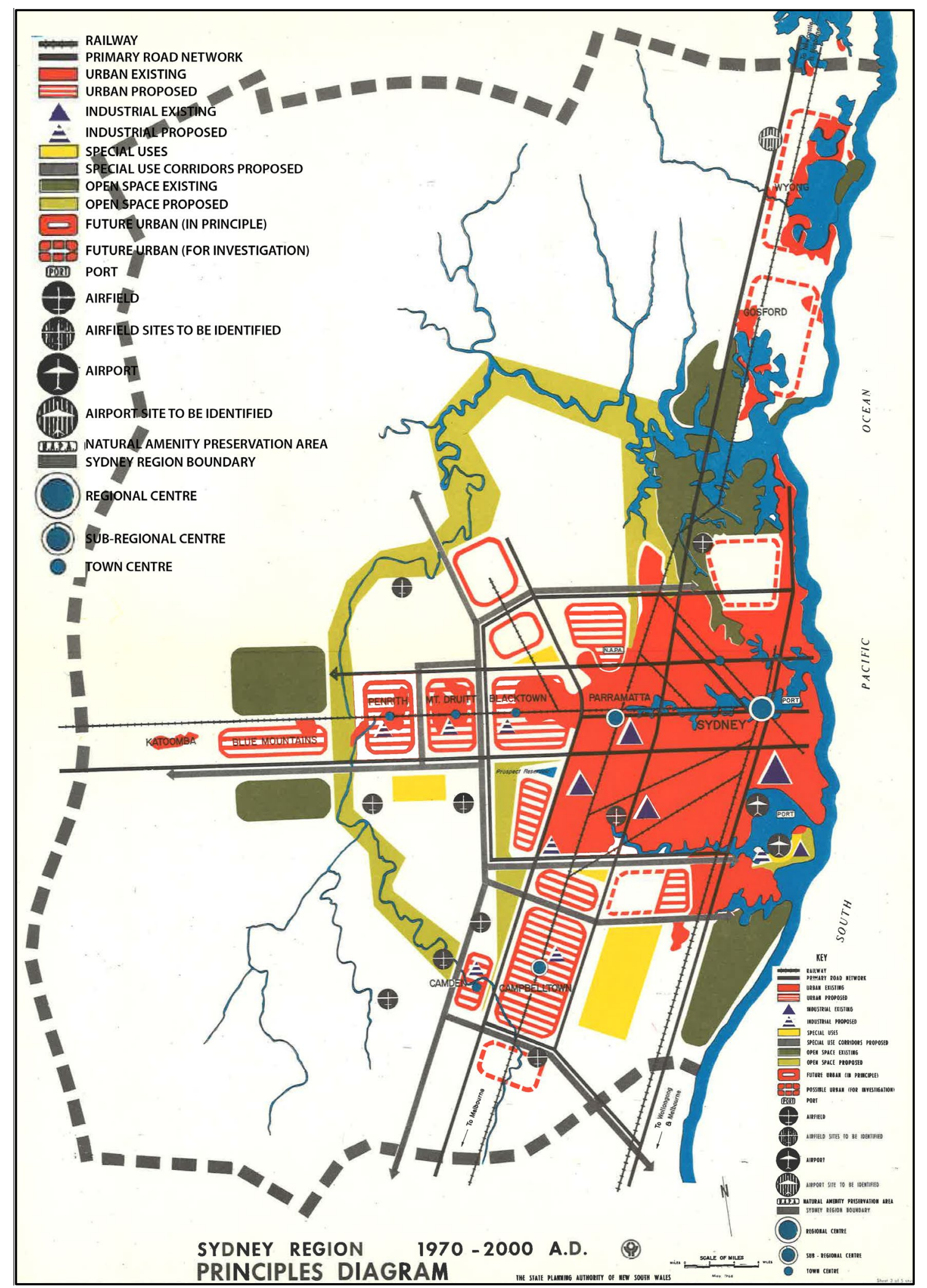

Figure 1. Sydney Region 1970-2000 Principles Diagram.

Source: NSW SPA, 1968, np. Key redrawn.

While the SROP also aims to support macroregional integration, we focus on the intraregional corridors which endure to the 2018 metropolitan strategic plan. The SROP principles diagram in Figure 1 draw dominant lines following existing roads and railways 
horizontally, and also transecting north to south, proposing new urban areas and areas for investigation. Similar to recent strategic plans, the SROP strategy sought to break the dominant agglomeration of the Sydney CBD and North Sydney business districts which together monopolised office development in the metropolitan region. This strategy of decentralisation was also intended to 'decentralise jobs to coincide as far as possible with the location of the new residents extensions' (NSW PEC 1980, p. 22). On the one hand is the aim to decentralise development in the metropolis, while on the other, there is an inherent path dependency linked to previous investments in hard infrastructure. The interdependence of infrastructural investment and land-use development are principles long guiding metropolitan strategic planning, however, their implementation and integration are examples of enduring conflicts requiring more effective regional governance.

While there is patchwork success of the corridor strategy, the spatial imaginary of the corridor is relatively enduring, and the corridors have evolved towards becoming a central strategic component of metropolitan plans. Responding to a dialectic pull of local and global drivers, corridors have both proliferated throughout the metropolis, and gained support through rhetorical strategy which is instrumental to closing the gap between path dependence and moving towards alternative destinations (Coaffee and Deas 2008). An example in the 2005 Sydney metropolitan strategy is the 'Global arc'. The spatial imaginary of the 'Global arc' draws a corridor connecting Sydney airport in the south, through the Sydney CBD and Macquarie business park in the north. Searle notes that 'while the non-statutory nature of the Global Arc means that it does not override state or local government planning decisionmaking, it has nevertheless been used as a justification by both levels of government for intensified development along the Arc' (Searle 2013, p. 374). While a powerful metaphor for development, this strategy lacks the impetus or statutory mechanisms to rebalance development across the metropolitan region. A different approach is required to shift developmental tendencies against a dominant path dependency, shifting locational preferences of business centres and residential areas. Since the 1980s, NSW Government policy has gradually relocated public sector jobs from the Sydney CBD to Parramatta. This has had some impact due to the sheer volume of workers that moved, but not enough to rebalance development across the region.

The 2018 metropolitan strategic plan, 'A metropolis of three cities' is the first metropolitan strategy in 50-years to be produced by a metropolitan governance authority. Produced by the GSC, it sets the framework for a 20-year plan, and a 40-year vision to rebalance the metropolis and integrate two state-level strategies, the 2018 State Infrastructure Strategy 2018-2038 (SIS) and 2018 Future Transport Strategy 2056 (FTS). Reviewing these three documents together, we see a complementary association with corridors. The FTS defines 'corridor' as a 'broad linear geographic area between places' (NSW Government 2018 p. 159). The FTS also identifies a hierarchy of corridors from 'city-shaping', 'city-serving' and 'centre-serving' corridors primarily servicing vehicle and public transport capacity in the first two categories, while the latter supports greater modality including walking and cycling within city centres (NSW Government 2018, p. 34). 
The SIS, takes a more strategic approach in identifying the value of integrating land-use and infrastructure, and suggests corridors as the space where it can occur (INSW 2018, p. 31). The SIS identifies the 'Eastern Harbour City' as 'Australia's global economic gateway' with the eastern economic corridor accounting for 24 per cent of Australia's GDP growth in the 2015-16 financial year (INSW 2018, p. 105). This is an interesting measure, as there is no statutory definition of the eastern economic corridor thus giving license to interpret where the fuzzy boundary ends. The GPOP is labelled a 'renewal corridor (INSW 2018, p. 108), a lingering badge attached to previous metropolitan strategies calling for the renewal of the Parramatta Road corridor. Western Sydney, as primarily greenfield land requires corridor protection for a planned Western Sydney Aerotropolis (WSA) (INSW 2018, p. 111).

While the FTS and SIS strategies are guided by the GSC metropolitan strategy, the GPOP and WSA are not acknowledged as economic corridors, but spatial imaginaries positioned as supporting actors to the dominant global economic corridor. This is an interesting point, tracing the development from draft to finalised strategies from 2016 - 2018, a gradual transition can be observed shaping the discourse within the metropolitan plans to centre Parramatta and its extended spatial imaginary of the GPOP relative to ' $a$ ' centre (the existing Sydney CBD), towards becoming 'the' centre of the Sydney metropolis (Pham 2018). Placing the GPOP and WSA in the shadow of the eastern economic corridor may affect wider perceptions about the role of the GPOP as the centre of the metropolis, and hinder pathways towards rebalancing the metropolis. The following section traces the evolution of the GPOP, and its promotion from a renewal corridor, to a city-shaping strategy and central to rebalancing the metropolis.

\section{Real and imagined spaces}

This article has so far suggested that spatial imaginaries perform a steering role, strategically guiding development in metropolitan regions. They can also harden, that is, take a statutory form, shaping, more concretely what can be done, and where. It should be noted that softness and hardness are not mutually exclusive but may exist on a continuum, and may coexist in both forms (Metzger and Schmitt 2012). The recent emergence of hardening spatial imaginaries in the Sydney metropolis responds to the need to more actively shape development pathways, and reshape existing metropolitan topologies. In the case of Sydney, this process is central towards achieving the metropolitan growth priority of rebalancing the region, not only from a monocentric to polycentric metropolis, but also towards greater alignment of employment and residential centres with the aim of reducing infrastructure servicing costs, and travel times (GSC 2018). This section traces the assemblage of plans and strategies informing the development of the GPOP FEC, constructed through prior spatial imaginaries. We identify key moments which have led to their current form focussing in particular the complexities of defining the nexus to infrastructure contributions and development within the GPOP.

The 2005 metropolitan strategic plan defines corridors as 'areas around the transport routes that connect centres and activities' (NSW Department of Planning 2005, p. 81). While the 
Parramatta Road corridor has been acknowledged since the 2005 metropolitan plan, it has developed more clearly into a strategically significant spatial imaginary in the 2014 metropolitan plan. Previous strategic plans have identified the Parramatta CBD within other configurations including employment clusters and economic centres, but this has not explicitly been attended to as a corridor, or functioning in a comparable way. Consultation of the Parramatta Road corridor began in 2013 led by NSW Government agency, Landcom, with a final strategy produced in 2016, and given a short term implementation timeline ending in 2023.

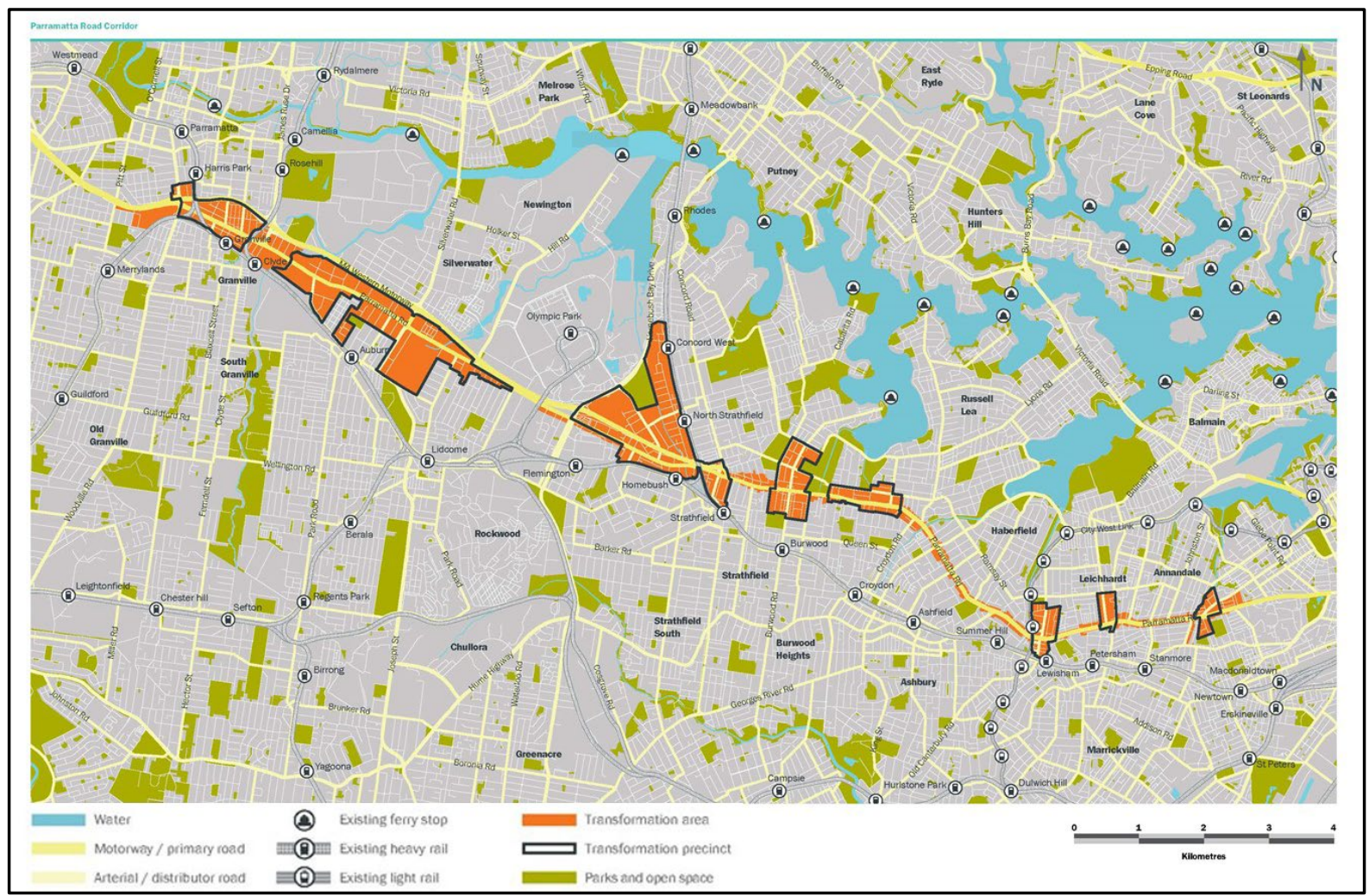

Figure 2. Parramatta Road Corridor

Source: NSW Government 2016, pp. 14-15. Key redrawn.

The Parramatta Road corridor spans for 20 kilometres, linking several non-contiguous precincts with differing typologies apportioned for semi-industrial, mixed use and cosmopolitan development axes highlighting renewal opportunities (see Figure 2 above). While the Parramatta Road corridor transformation strategy (separate from metropolitan planning documents) sees the centrality of Parramatta Road, the 2014 metropolitan strategy identifies centres informed by land-use anchored by Parramatta which is envisaged as an "extension of the Global Economic Corridor" (NSW Department of Planning 2014, p. 34). As these spatial imaginaries partially overlap, it becomes increasingly important to have a common governance body leading/guiding their development, integration and delivery. And although the entire Parramatta Road corridor extends for 20 kilometres to the Sydney CBD, 
we are interested in its western stretch from Granville to Homebush, an area which overlaps with the Greater Parramatta Growth Area, and together form the basis for the GPOP FEC.

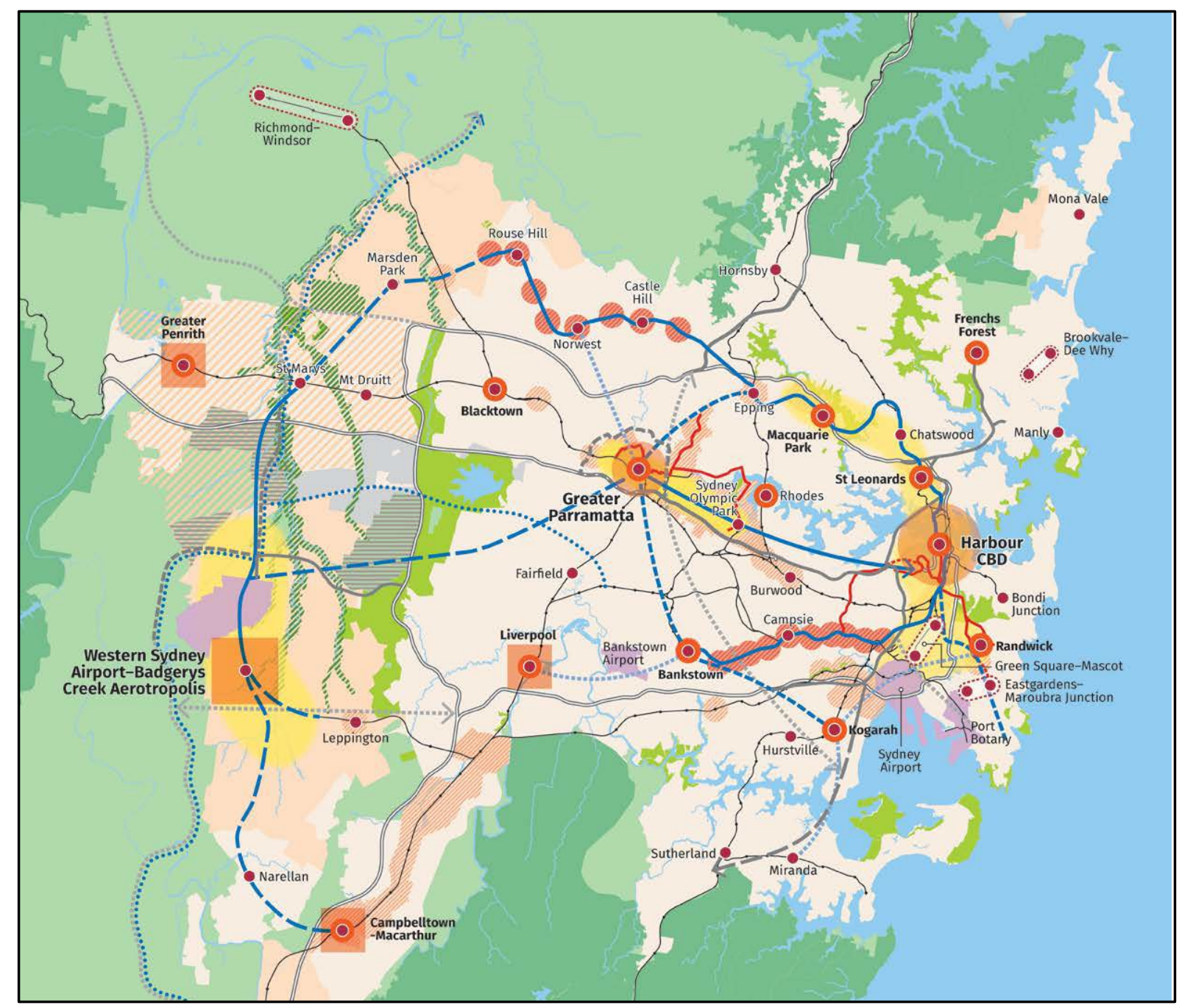

Figure 3. Greater Sydney Region Structure Plan

Source: GSC 2018, p. 15.

The centrality of greater Parramatta in relation to the metropolitan region supports the positioning of the GPOP as both strategically and geographically central, a detail not missed by the most recent 2018 metropolitan plan. While the GPOP is situated in the geographic middle of the metropolis (see Figure 3), it must also contend with a longstanding social and geographical divide between the 'affluent' east, and 'less developed' western Sydney, requiring greater investment, development and intra-regional connectivity to bridge this longstanding gap. While the eastern suburbs can take advantage of their advantageous position catching the cooling easterly sea breeze, the western suburbs sandwiched between the eastern suburbs and the Great Dividing Range, a natural geographic border in the west leading to much drier and warmer environments. This condition impacts on the health of residents and their amenity requiring greater resilience efforts to mitigate the urban heat island effect (GSC 2019). We acknowledge that these social and environmental differences 
and their role in shaping metropolitan strategies are important, but lacking the space in this article, we concentrate our discussion on the strategic/statutory boundary shaping greater infrastructural and land-use decisions, and the shape and location of spatial imaginaries in the metropolis.

The GPOP, as a strategically important site, is also a site of planning and governance innovation. A varied range of delivery authorities have experimented with different mechanisms and strategies to integrate silos and hierarchies of government, coordinating infrastructure delivery and land-use planning. The most recent of these is the GSC, an independent government agency tasked with leading metropolitan planning for the Greater Sydney Region and promote development and alignment of infrastructure decision-making with land-use planning. The GSC has proposed a Growth Infrastructure Compact (GIC) to 'match housing and jobs growth with timely and cost-effective delivery of infrastructure' (GSC 2017, np). As the path-dependency adhered to the timing of infrastructure delivery and its location, it is critical to evaluate where, how and when infrastructure should be delivered before the development of detailed strategic land-use plans.

Together, the Parramatta Road corridor, and GPOP are strategically significant spatial imaginaries co-shaping their development trajectories and the interconnectivities with the metropolitan region through transport and infrastructure investments, primarily motorway and a mixture of rail projects. While the GPOP is central to these two spatial imaginaries, collaboration and engagement is required with a series of councils, state government departments and special purpose delivery authorities, including the GSC. Public engagement is also mandated with the wider community. This complex organisational assemblage hides the temporal dimension modifying prior strategic priorities, shaping strategic documents and its spatial representation. In particular, the evolution of the GPOP FEC advancing from a nebulous representation of fuzzy areas, are given distinct functional areal identities with four spatially distinct quarters categorised through residential, lifestyle, health and a CBD core specialisation (NSW Government 2017). Although the GPOP already to a certain extent captures these employment sectors, it also demonstrates the policy direction of strengthening industries around the Parramatta CBD and Olympic Park over light industrial and manufacturing present in the middle of the GPOP. These industries are primarily knowledge, health and education jobs, and a revitalisation of the Olympic Park precinct that was initially developed for the Sydney Olympic Games (2000). And as these intra-corridor areas gain their respective identities, the GPOP FEC, previously recognised through its strategic extent in earlier metropolitan strategies, also hardens, and gains a draft statutory boundary legislating the extent of the GPOP.

The GPOP draft statutory boundary (see Figure 4, black outline) has been recognised under the NSW State Environmental Planning Policy (Sydney Region Growth Centres), covering parts of Ryde, Canada Bay, Strathfield and Cumberland LGA, although predominately drawn over Parramatta LGA (see Figure 4, red outline). This is significant as the GPOP gains statutory weight, planning policies associated with the GPOP override statutory local government plans including Local Environment Plans and Development Control Plans which can lead towards land use planning conflicts (Pham and Pugalis 2019). 


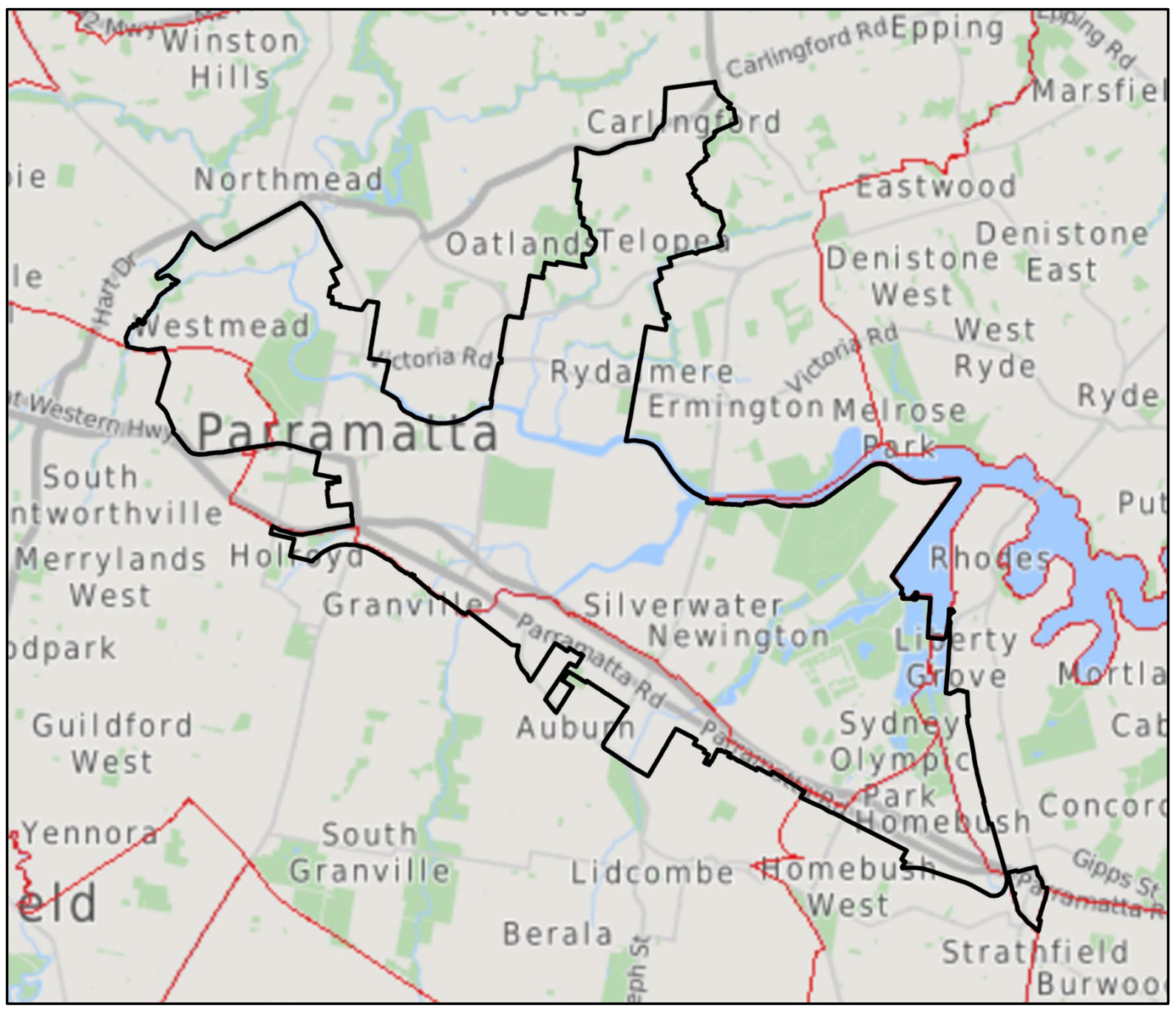

Figure 4. GPOP draft statutory boundary and LGA boundary overlap

Source: By the author using Australian Bureau of Statistics and NSW Government data.

As the strategic soft space of the GPOP hardens to a statutory legislative document, land-use conflicts become open to interrogation and uncertainty as proponents will need to consider a range of local and state significant priorities under a raft of overlapping strategies. For example, development contributions are levied to fund infrastructure at local, regionally significant and 'city-shaping' projects. Given these categories, development proponents may need to consider multiple legislative requirements, and mix of state and council-led planning and rezoning. These concerns have been signalled against the Greater Parramatta Interim Land Use and Infrastructure Implementation Plan (ILUIIP) (2017) yet to be finalised, where in NSW, greater transparency is required for proponents to understand what their development contributions are funding (UDIA 2017; Robinson and de Gruyter 2017). Clarifying these conflicts becomes increasingly important in a complex strategic space like the GPOP. As a FEC that is significant to the success of the 'metropolis of three cities', and considering the quanta of infrastructure and development required for the GPOP to compete with the Sydney CBD, apportionment of infrastructure and costs should be clarified before detailed strategic and land-use planning (Infrastructure Australia 2016). 
These uncertainties get at the heart of the planning-governance nexus so important to the processes and practices of metropolitan governance (Schmitt and Danielzyk 2018) which can be interrogated through spatial imaginaries such as the GPOP. The GPOP is a space requiring the cooperation and collaboration of a range of governments and government silos working in partnership to deliver integrated spatial outcomes. The effectiveness of these arrangements requires transparency and certainty between stakeholders to promote trust and understanding of common strategic goals which may be reached by stakeholders in partnership, agreeing on the nexus between development and infrastructure.

To take the infrastructure funding dimension in priority precincts such as the GPOP, to support the accelerated growth of the precinct will require additional funding to provide infrastructure, transport and community facilities to support this growth. In the GPOP, several state significant infrastructure projects including the WestConnex motorway, Parramatta light rail and Sydney Metro West are underway to better connect the GPOP to the rest of the metropolis. These projects are paid for by a complex assemblage of funding arrangements involving all levels of government and also in partnership with the private sector. While these largescale projects offer greater clarity to their purpose to the wider region and can be apportioned correspondingly, precinct scale improvements including public domain and community infrastructure may be less clear as they may not be deemed essential and their relationship to the wider GPOP FEC. Although less transformative in connecting people and places, the quanta of community infrastructure projects should grow with communities as they increase in population. The conflicts and complexities that emerge as soft spaces harden illustrate the importance of borders and the need for greater attention to their alignment and tensions given to different priorities taken by a diverse range of stakeholders contributing to the development of spatial imaginaries and FECs.

\section{Conclusion}

This article has drawn attention to the complexities and challenges of rebalancing the Sydney metropolis with FECs through a theoretical scaffold integrating spatial imaginaries and borders. We have shown that FECs are strategically significant spaces important to achieving metropolitan growth priorities. Although corridors have been utilised since the 1960s, their function and application have evolved beyond merely preserving land for the development of infrastructure. Corridors are central to achieving metropolitan strategy.

While strategic spaces often overlap, the GPOP introduces further complexity by taking a subsequent statutory form. The GPOP as a sub-regional space interlaces with existing local government borders producing conflicts in defining the area and extent of contributions required from proponents requiring greater clarity and its cumulative impact for land-owners. Conflicts emerge in addition to financial contributions, but also require clarity identifying what these contributions are paying for, that is, the nexus between development and infrastructure. These conflicts underscore the importance of paying attention to how and where borders are drawn and the growing importance of spatial imaginaries especially as their edges harden to achieve a statutory form. Often utilised as a strategic soft space, there 
are additional considerations which require attention as they harden (Metzger and Schmitt 2012). While clarity and transparency is recommended, a space to question and innovate structures of metropolitan governance should remain as the drivers and context of metropolitan regions remains in constant motion.

In particular, this article has drawn attention to the evolution and changing function of corridors from simply preserving land for infrastructure, towards their role in steering the development of integrated precincts which are central to achieving metropolitan growth priorities. And while strategically significant, the infrastructure/funding nexus within spatial imaginaries needs to be more clearly articulated, perhaps engaging with both community and development proponents, aligning the perspectives of these stakeholders with government policy. Whatever their form, spatial imaginaries and their governance should continue to address the broader local and global drivers addressing metropolitan regions.

\section{References}

Albrechts, L., and T. Tasan-Kok. 2009. “Corridor and Axis Development.” In International Encyclopedia of Human Geography, edited by Rob Kitchin and Nigel Thrift, 298-304. Oxford: Elsevier.

Allmendinger, Phil, and Graham Haughton. 2009. "Soft Spaces, Fuzzy Boundaries, and Metagovernance: The New Spatial Planning in the Thames Gateway." Environment \& Planning A 41 (3): 617-33.

Allmendinger, Phil, Graham Haughton, Jörg Knieling, and Frank Othengrafen. 2015. "Soft Spaces, Planning and Emerging Practices of Territorial Governance." In Soft Spaces in Europe: Re-Negotiating Governance, Boundaries and Borders, edited by Phil Allmendinger, Graham Haughton, Jörg Knieling, and Frank Othengrafen, 3-22. Oxon: Routledge.

Anderson, James, and Liam O’Dowd. 1999. "Borders, Border Regions and Territoriality: Contradictory Meanings, Changing Significance.” Regional Studies 33 (7): 593-604.

Baker, Tom, and Kristian Ruming. 2015. "Making 'Global Sydney’: Spatial Imaginaries, Worlding and Strategic Plans." International Journal of Urban and Regional Research 39 (1): $62-78$.

Blatter, Joachim. 2004. 'From 'Spaces of Place' to 'Spaces of Flows'? Territorial and Functional Governance in Cross-Border Regions in Europe and North America." International Journal of Urban and Regional Research 28 (3): 530-48.

Burridge, Andrew, Nick Gill, Austin Kocher, and Lauren Martin. 2017. "Polymorphic Borders.” Territory, Politics, Governance 5 (3): 239-51.

Coaffee, Jon, and Iain Deas. 2008. "The Search for Policy Innovation in Urban Governance: Lessons from Community-Led Regeneration Partnerships." Public Policy and Administration 23 (2): $167-87$. 
Dollery, Brian, Bligh Grant, and Michael Kortt. 2013. "An Evaluation of Amalgamation and Financial Viability in Australian Local Government." Public Finance \& Management 13 (3).

Grant, Bligh. J., Roberta Ryan, and Alex Lawrie. 2015. “Reforming 'Sydney Global City': Mapping Enduring Sites of Institutional Conflict." In 14th Annual Society for Heterodox Economists (SHE) Conference. SHE; UNSW Business School.

Greater Sydney Commission (GSC). 2019. "The Pulse of Greater Sydney: Measuring what matters in the Metropolis."

Greater Sydney Commission (GSC). 2018. "Greater Sydney Region Plan: A Metropolis of Three Cities."

Greater Sydney Commission (GSC). 2017. "Growth Infrastructure Compacts: Planning, Prioritising and Coordinating Infrastructure to Deliver a Greater Sydney."

Gurran, Nicole, and Kristian Ruming. 2016. "Less Planning, More Development? Housing and Urban Reform Discourses in Australia." Journal of Economic Policy Reform 19 (3): 26280 .

Hamnett, Stephen, and Robert Freestone. 2018. Planning Metropolitan Australia.

Oxfordshire: Routledge.

Haughton, Graham, and Philip Allmendinger. 2017. "Alternative Planning Spaces." In Territorial Policy and Governance: Alternative Paths, edited by Iain Deas and Stephen Hincks, 95-113. Routledge.

Haughton, Graham, and Philip Allmendinger. 2015. "Fluid Spatial Imaginaries: Evolving Estuarial City-Regional Spaces." International Journal of Urban and Regional Research 39 (5): 857-73.

Haughton, Graham, and Phil Allmendinger. 2008. "The Soft Spaces of Local Economic Development." Local Economy 23 (2): 138-48.

Haughton, Graham, Philip Allmendinger, David Counsell, and Geoff Vigar. 2010. The New Spatial Planning: Territorial Management with Soft Spaces and Fuzzy Boundaries. Routledge.

Healey, Patsy. 2007. Urban Complexity and Spatial Strategies: Towards a Relational Planning for Our Times. Oxon: Routledge.

Hincks, Stephen, Iain Deas, and Graham Haughton. 2017. "Real Geographies, Real Economies and Soft Spatial Imaginaries: Creating a 'more than Manchester' region." International Journal of Urban and Regional Research 41 (4): 642-57.

Independent Local Government Review Panel (ILGRP). 2013. "Future Directions for NSW Local Government - Twenty Essential Steps.” 
Infrastructure Australia. 2016. "Capturing Value: Advice on Making Value Capture Work in Australia.” Reform Series, Infrastructure Australia, Australian Government, Canberra.

Infrastructure NSW (INSW). 2018. "Building Momentum: State Infrastructure Strategy 2018-2038."

Metzger, Jonathan, and Peter Schmitt. 2012. "When Soft Spaces Harden: The EU Strategy for the Baltic Sea Region.” Environment \& Planning A 44 (2): 263-80.

Morison, Ian. 2000. "The Corridor City: Planning for Growth in the 1960s." In The Australian Metropolis, edited by Stephen Hamnett and Robert Freestone, 113-30. Crows Nest: Allen \& Unwin.

Newman, David. 2011. "Contemporary Research Agendas in Border Studies: An Overview." In The Ashgate Research Companion to Border Studies, edited by Doris Wastl-Walter, 3347.

New South Wales (NSW) Department of Planning. 2014. A Plan for Growing Sydney. Sydney: NSW Government.

New South Wales (NSW) Department of Planning. 2005. City of Cities: A Plan for Sydney's Future. Sydney: NSW Government.

New South Wales (NSW) Government. 2018. Future Transport Strategy 2056. Sydney: NSW Government.

New South Wales (NSW) Government. 2017. Greater Parramatta Interim Land Use and Infrastructure Implementation Plan. Sydney: NSW Government.

New South Wales Planning \& Environment Commission (NSW PEC). 1980. "Review Sydney Region Outline Plan."

New South Wales State Planning Authority (NSW SPA). 1968. Sydney Region: Outline Plan 1970-2000 AD: A Strategy for Development. State Planning Authority of New South Wales.

Paasi, Anssi. 2009. "Bounded Spaces in a 'borderless World': Border Studies, Power and the Anatomy of Territory." Journal of Power Sources 2 (2): 213-34.

Paasi, Anssi, and Kaj Zimmerbauer. 2015. "Penumbral Borders and Planning Paradoxes: Relational Thinking and the Question of Borders in Spatial Planning." Environment \& Planning A 48 (1): 75-93.

Pham, Kane. 2018. "Bordering Practices in Global Sydney: Becoming a City-Region or a 'Metropolis of Three Cities'?" In Metropolitan Governance in Asia and the Pacific Rim: Borders, Challenges, Futures, edited by Bligh Grant, Cathy Yang Liu, and Lin Ye, 57-72. Singapore: Springer Singapore.

Pham, Kane and Lee Pugalis. 2019. "Conflict and contradictions of multiple hard planning spaces.” In State of Australian Cities Conference. SOAC; UWA Perth 
Pugalis, Lee, and Alan R. Townsend. 2014. "The Emergence of 'new' Spatial Coalitions in the Pursuit of Functional Regions of Governance." Regional Science Policy \& Practice 6 (1): 49-67.

Robinson, Joshua, and Chris De Gruyter. 2017. "Financing Infrastructure through User-Pays Development Contributions: An Assessment of Australian Practice." Australian Planner 54 (3): 165-76.

Schmitt, Peter, and Rainer Danielzyk. 2018. "Exploring the Planning-Governance Nexus." disP - The Planning Review 54 (4): 16-20.

Searle, Glen. 2013. "'Relational' Planning and Recent Sydney Metropolitan and City Strategies." Urban Policy and Research 31 (3): 367-78.

Spearritt, Peter, and Christina DeMarco. 1988. Planning Sydney's Future. Sydney: Allen \& Unwin.

Steele, Wendy, and Kristian J. Ruming. 2012. "Flexibility versus Certainty: Unsettling the Land-Use Planning Shibboleth in Australia." Planning Practice \& Research 27 (2): 155-76.

Steele, Wendy, Tooran Alizadeh, and Leila Eslami-Andargoli. 2013. "Planning across Borders." Australian Planner 50 (2): 96-102.

Swyngedouw, Erik. 2004. "Globalisation or 'glocalisation'? Networks, Territories and Rescaling." Cambridge Review of International Affairs 17 (1): 25-48.

Tomlinson, Richard, and Marcus Spiller. 2018. Australia's Metropolitan Imperative: An Agenda for Governance Reform. Csiro Publishing.

UDIA. 2017. Greater Parramatta - Interim Land Use and Infrastructure Implementation Plan Submission.

Yanow, Dvora. 2006. "Neither Rigorous Nor Objective? Interrogating Criteria for Knowledge Claims in Interpretive Science." In Interpretation and Method: Empirical Research Methods and the Interpretive Turn, edited by Dvora Yanow and Peregrine Schwartz-Shea, 67-88. M.E. Sharpe.

Yanow, Dvora. 2007. "Interpretation in Policy Analysis: On Methods and Practice." Critical Policy Studies 1 (1): 110-22. 